EESTI NSV TEADUSTE AKADEEMIA TOIMETISED. 21. KÖIDE

KEEMIA * GEOLOOGIA. 1972, NR. 2

ИЗВЕСТИЯ АКАДЕМИИ НАУК ӘСТОНСКОЙ ССР. ТОМ 21

ХИМИЯ * ГЕОЛОГИЯ, 1972, № 2

УдіК $551.733 .12[485+474]: 56.016 .6$

\title{
Р. МЯННИЛЬ
}

\section{КОРРЕЛЯЦИЯ ВЕРХНЕВИРУСКИХ ОТЛОЖЕНИЙ (СРЕДНИЙ ОРДОВИК) ШВЕЦИИ И ПРИБАЛТИКИ ПО ХИТИНОЗОЯМ}

Отложения верхней половины свиты Далбю и свиты Скаген, благодаря работе C. Лауфельда (Lauield, 1967), представляют собой в настоящее время наиболее изученный в отношении хитннозой интервал сводного разрєза ордовика Швеции. Наиболее ценной информацией выделяется разрез Фьяка района оз. Сильян, обработянный С. Лауфельдом серией мелких проб в интервале 22,0-40,4 м (Laufeld, 1967, рис. 2). В этом интервале им обнаружены 23 вида хитинозой, почти половина из которых была встречена только в узких интервалах разреза и представляет интерес как возможные руководящие формы. Доказать их руководящую роль можно, однако, лишь специальным изучением распределения хитинозой в одновозрастных отложениях других разрезов, так как опубликованные до сих пор данные о распределении хитинозой в Прибалтике (Eisenack, 1962, 1968) для этой цели явно недостаточны.

Результаты, полученные автором за последние годы по изучению распределения хитинозой в разрезах Прнбалтики, в частности Северной Эстонии, позволяют дать биостратиграјфическую оценку встречаемости хитинозой в разрезе Фьяка и одновременно использовать соответствующую информацию для обоснования и уточнения корреляции рассматриваемых отложений Швеции и Прибалтики.

В отношении Прибалтики настоящая статья иллюстрируется разрезами лишь двух буровых скважин - Кандава-25 в Западной Латвии и Вярска на юго-востоке Эстонии (см. рисунок), керны которьіх изучались на хитинозои неравномерно и по сравнению с другими разрезами Прибалтики не оссбенно детально. Однако именно в этих двух разрезах, расположенных вместе с разрезом Фьяка в одной и той же Шведско-латвийской фашиальной зоне, до сих пор установлено нанбсльшее число зон хитинозой, общих с разрезом Фьяка. Оценка этих зон, а также рассмотрение распределения некоторых других видов хитинозой основываются при этом в значительной части на результатах изучения серийных проб ряда других разрезов.

За помощь, оказанную при обработке проб на хитинозои, автор многим обязап сотрудникам Института геологии АН ЭССР Л. Хинтс, Х. Партс и Я. Нылваку. Керн скв. Кандава-25 был любезно предоставлен нам для изучения бывшим главным геологом Нефтепоисковой экспедиции Управления геологии при СМ ЛатвССР В. Қарпицким, а пробы из скв. Вярска - начальником геологического отдела У'правления геология СМ! ЭССР П. Вингисааром.

В разрезе Фьяка (см. рисунок) хитинозои в свите Далбю присутствуют только в верхней $2 / 3$ части ее; в нижней части свиты они, видимо, уничтожены в процессе диагенеза:(или эпигенеза?). Рассматриваемые в данной статье отложения, таким образом, в разрезе Фьяка разграничены снизу уровнем диагенетически обусловленного «появления» хитинозой и сверху условной верхней границей свиты Скаген. Они охватывают практически весь комплекс прослоев метабентонитов среднего ордовнка Прибалтики и Швеции и согласно корреляции, основываю- 
щейся на раковинной фауне, грубо соответствуют интервалу разреза Прибалтики от верхов кукрузеского горизонта $\left(\mathrm{C}_{\mathrm{II}}\right)$ до кровли кейлаского (DII) (Jaanusson, 1963; Мянниль, 1966; Laufeld, 1967). Этот интервал, за исключением самых низов, характеризуется во всей Прибалтике обильным присутствием крупных форм Leiosphaeridia и Tasmanites, что четко отличает рассматриваемые ассоциации кислотоустойчивых микрофоссилий от ассоциаций остальной части среднего, а также верхнего ордовика.

Приуроченные к данному интервалу прослои метабентонитов, широко распространенные в Скандинавии и на северо-западе Прибалтики, являются его другой своеобразной чертой; эти прослои независимо от палеонтологических данных служат хорошими реперами времени и могут быть успешно использованы в целях корреляции вмещающих их отложений (см. Мянниль, 1966; Рыымусокс, 1970). Количество и характер распределения метабентонитов в рассматриваемых разрезах, однако, резко различаются. В разрезе Кандава-25 Л. Пылма и Л. Хинтс обнаружили 12 прослоев, сконцентрированных главным образом в верхней $2 / 3$ части данного интервала; основной слой их залегает на глубине * 924,2-924,4 м. В разрезе Фьяка метабентониты, за исключением единичного прослоя в верхах кукрузеского горизонта, присутствуют только в узком ннтервале мощностью около 1,8 м, сверху срезанном сбросом (Јaаnusson, Martna, 1948). В разрезе Вярска, по данным П. Вингисаара, метабештониты вообще не обнаружены.

На основании распределения характерных, в том числе зональных видов хитинозой, рассматриваемые отложения могут быть во всех трех разрезах расчленены сверху вниз на следующие слои (зоны):

(V) слои с Desmochitina juglandiformis;

(IV) слои с Desmochitina sp. n.;

(III) слои с Conochitina hirsuta;

(II) слои с Eremochitina dalbyensis;

(I) слои с Conochitina tigrina.

Ниже остановимся на характеристике и корреляции рассматриваемых верхневируских отложений по указанным пяти подразделениям.

\section{Слои с Conochitina tigrina}

В разрезе Фьяка вид Conochitina tigrina установлен в интервале около $36,4-38,9 \mu$ (по С. Лауфельду, в интервале $8,1-10,6 м$ выше основания свиты Далбю; см. также Jaanusson, 1963, рис. 9, 10), где он встречается совместно с Cyathochitina stentor, Desmochitina lecaniella, D. rugosa и рядом других видов, имеющих в большинстве случаев широкий вертикальный диапазон распространения. Из них Cyathochitina stentor, однако, по имеющимся данным, нигде не поднимается выше указанных слоев и можно предположить, что кровля его зоны более или менее точно совпадает с кровлей зоны C. tigrina.

На основании распределения некоторых характерных видов раковинной фауны слои разреза Фьяка, рассматриваемые здесь как слои с $C$. tigrina отнесены нами к верхам кукрузеского горизонта (Мянниль, 1966, рис. 19).

В разрезе Кандава-25 C. tigrina установлен в интервале 930,4-930,5 , где его сопровождают Cyathochitina stentor и ряд характерных граптолоидей - Nemagraptus sp., Orthograptus uplandicus, Climacograptus cf.

* Глубины скв. Кандава-25 приняты по разрезу, составленному Л. Пылма и Л. Хинтс в 1970 г. без учета результатов каротажа. 
kuckersianus, Pseudoclimacograptus sp. n., Corynoides sp. На 0,3 $м$ ниже этого ннтервала найден руководящий для кукрузеского горизонта граптолит Amplexograptus bekkeri. На 0,4 $м$ выше интервала наблюдаегся массовое появление крупных акритарх; на этом же уровне (гл. 930,0 ) встречеп узкий зональный вид Cyathochitina sp. n. (aff. stentor), известный с того же стратиграфического уровня в нескольких скважинах центральной Эстонии. Все это говорит в пользу отнесения слоев с C. tigrina разреза Кандава-25 также к самым верхам кукрузеского горизонта с условной верхней границей на глубине около 930,2 $м$.

В скв. Вярска C. tigrina установлен пока только в двух пробах в интервале $381,9-382,3$ м; вместе с ним и здесь найдены Cyathochitina stentor, Pseudoclimacograptus sp. n., Nemagraptus sp., а также крупная (длинношейная) форма вида Cyathochitina campanuiaeformis.

Кроме указанных трех разрезов, C. tigrina установлен на этом же стратиграфическом уровне еще в скважннах Лаэва (гл. 257,3 м), Эммасте (гл. 191,7 м) и в некоторых других. Это говорит о том, что C. tigrina образует зону, прослеживаемую на значнтельной территории. Кровля этой зоны, насколько можно судить по разрезам центральной и западной части Әстонии, находится несколько ниже основания зоны Eremochitina dalbyensis, причем к промежуточным слоям, по крайней мере в Прибалтике, приурочены снизу вверх еще зона (?) Conochitina sp. $\mathrm{n}$. (= ? C. differens Dicevitchius), зона Cyathochitina sp. n. (aff. stentor) и зона Angochitina sp. n. Возможно, что слои, соответствующие указанным трем зонам, в Швеции и Средней Прибалтике отсутствуют или представлены очень маломощными отложениями. Эти слои относятся, очевидно, уже целиком к зоне Diplograptus multidens, так как граница между конодонтовыми подзонами Prioniodus variabilis и Prioniodus gerdae сопоставляемая С. Бергстрёмом (Bergström, 1971a, в) с кровлей зоны Nemagraptus gracilis, залегает в разрезе Фьяка в пределах верхней половины слоев с Conochitina tigrina.

\section{Слои с Eremochitina dalbyensis}

Эти слои представляют собой отлично прослеживаемую зону, которую можно считать одной из самых лучших реперов корреляции ордовикских отложений данного регисна (Männil, 1971). К настоящему времени она установлена в Швеции, во всей Прибалтике и на западе Ленинградской области - общим числом более, чем в 15 пунктах. Мощность зоны может достигать 60 м (скв. Палукюла), но обычно составляет 2 -3 м. В скв. Вярска зональный вид был встречен только в одной пробе; это, вероятно, объясняется недостаточно полным отбором проб. В скв. Кандава-25 в данной зоне найден Pseudoclimacograptus scharenbergi f. typica.

Слои с Eremochitina dalbyensis относятся к стратотипической части разреза идавереского горизонта $\left(\mathrm{C}_{\mathrm{III}}\right)$.

\section{Слои с Conochitina hirsuta}

Слои с Conochitina hirsuta возможно, также представляют собой зону** данного вида, так как кроме трех рассматриваемых в настоящей статье разрезов этот вид найден нами на том же стратиграфическом

** Под зоной мы подразумеваем здесь полную амплитуду вертикального распространения вида в дапном регионе; отдельные части зон, изолированные друг от друга пустыми интервалами, мы называем условно «зонулами», обозначая их после довательность буквами А, B, C, ... 
уровне еще в ряде других скважин (Эммасте, Румба, Виру-Роэла и др.). Мощность зоны в разрезе Фьяка около 3 , в скв. Кандава-25 $1,5-2 \mu$.

В разрезе Фьяка нижняя граница зоны Conochitina hirsuta находится в пределах интервала $13,2-14,5$ м, считая от основания свиты Далбю. В этот же интервал попадает нижняя граница подзоны Prioniodus alobatus (14,25 м), которая С. Бергстрёмом (Bergström, 1971, a, b) сопоставляется с границей между Портерфильдом и Рокландом Северной Америки. В скв. Вярска в зоне Conochitina hirsuta найден Amplexograptus cf. fallax, который в Северной Эстонии и Западной Латвии поднимается по разрезу до верхов кейлаского горизонта; в слоях, залегающих ниже данной зоны, A. cf. fallax нигде не встречен.

Приведенные данные позволяют нам отнести слои с Conochitina hirsuta к йыхвискому горизонту $\left(\mathrm{D}_{\mathrm{I}}\right)$, точнее к его нижней части.

\section{Слои с Desmochitina sp. n.}

Данные слои соответствуют первой зонуле (зонула А) вида Desmochitina sp. п. и выделяются в разрезе Кандава-25 между кровлей зоны C. hirsuta и главным метабентонитом (в интервале 924,8-926,6 м). Зонула эта выделяется также в скв. Вярска, но на территории Швеции она пока еще не обнаружена. В разрезе Фьяка ей грубо соответствует, вероятно, нижняя часть «зоны» Desmochitina piriformis.

Слои с Desmochitina sp. n. (зонула A), очевидно, соответствуют верхней части йыхвиского горизонта.

\section{Слои с Desmochitina juglandiformis}

В разрезах Фьяка и Кандава-25 эти слои соответствуют зонуле С Spinachitina multiradiata и залегают, в общем, над главным метабентонитом, покрываясь слоями (в разрезе Фьяка - макроурусовыми, в разрезе Кандава-25 - блиденскими), уже лишенными представителей рода Asaphus и относимыми к оандускому горизонту (D $\mathrm{III})$. На этом основании слои с Desmochitina juglandiformis в указанных разрезах можно считать одновозрастными, хотя этим еце не сказано, что возрастной объем их в обоих разрезах одинаков.

В разрезе скв. Вярска Desmochitina juglandiformis не найден, а Spinachitina multiradiata встречен стратиграфически выше, чем в разрезах Фьяка и Кандава-25. Несмотря на это, данные слои могут быть сопоставлены и в разрезах скважин Кандава- 25 и Вярска, если воспользоваться первым появлением в обоих разрезах Fungochitina fungiformis и вторым появлением Desmochitina sp. n. (зонула В) (см. рисунок).

C североэстонскими отложениями слои с Desmochitina juglandiformis, по имеющимся данным, лучше всего сопоставляются посредством разреза Кандава-25 и разрезов о. Хийумаа. В первом над главным слоем метабентонита присутствуют еще три тонких прослоя метабентонитов (см. рисунок). В разрезах о. Хийумаа (скв. Кыргессааре и др.), по данным Л. Хинтс, выше главного слоя метабентониты также встречаются на трех стратиграфических уровнях, причем самый верхний из них залегает в середине сауэских слоев (в скв. Орьяку на 3,3 м ниже кровли кейлаского горизонта). Над этим прослоем в скв. Орьяку обнаружены слои, содержащие Desmochitina sp. n. вместе с Amplexograptus cf. fallax. Эти слои, очевидно, соответствуют зонуле В Desmochitina sp. n. в разрезе Кандава-25, так как в ней также присутствует Amplexograptus cf. faliax и она характеризуется по сравнению с нижней частью слоев с 
D. juglandiformis обновленным составом комплекса хитинозой (отсутствуют Cyathochitina calix и Conochitina cf. dolosa, присутствуют Fungochitina fungiformis, Desmochitina sp. п. и Conochitina cactacea).

Итак, представляется весьма вероятным, что слои с Desmochitina juglandiformis разреза Кандава-25, несмотря на небольшую мощность $(2,6 \mu)$, целиком соответствуют всему североэстонскому разрезу кейлаского горизонта, мощность которого в скв. Кыргессааре достигает $23,4 \mu$ (Рыымусокс, 1970). Это в свою очередь заставляет отнести слои с D. juglandiformis разреза Фьяка (свита Скаген) и их возрастные аналоги в скв. Вярска также к кейласкому горизонту $\left(\mathrm{D}_{\text {II }}\right)$.

Таким образом, целый ряд видов хитинозой, установленных в верхневируских отложениях разреза Фьяка и имеющих там узкий диапазон вертикального распространения, действительно оказываются хорошими руководящими видами. Они могут успешно служить основой для детального зонального расчленения и сопоставления отложений, а также для прослеживания границ отдельных горнзонтов на значительные расстояния.

\section{Л И ТЕ Р А Т У Р А}

Мяннил в Р. M. 1966. История развития Балтийского бассейна в ордовике. Таллин.

Р ы ым ус окс А. 1970. Стратиграфия вируской и харьюской серий (ордовик) Северной Әстонин. 1. Таллин.

Bergström S. M. 1971, a. Conodont biostratigraphy of the Middle and Upper Ordovician of Europe and eastern North America. In: Symp. Conodont Biostratigraphy, Geol. Soc. Am. Mem., 127.

Berg ström S. M. 1971, b. Correlation of the North Atlantic Middle and Upper Ordovician Conodont zonation with the graptolite succession. In: Colloque ordoviciensilurien, Mem. Bureau Rech. Géol. et Min., No. 73.

E i sen a ck A. 1962. Mikrofossilien aus dem Ordovizium des Baltikums. 2. Vaginatenkalk bis Lyckholmer Stufe. Senck. leth., 43, Nr. 5.

E isen a ck A. 1968. Ober Chitinozoen des baltischen Gebietes. Palaeontographica, Abt. A, 131, Lief. 5-6.

$\mathrm{J}$ a a nus s on V. 1963. Lower and Middle Viruan (Middle Ordovician) of the Siljan district. Publ. Palaeont. Inst. Univ. Uppsala, 43.

$\mathrm{J}$ a a nus son V., Martna J. 1948. A section from the Upper Chasmops series to the Lower Tretaspis series at Fjäcka rivulet in the Siljan area, Dalarne. Bull. Geol. Inst. Uppsala, XXXII.

L a u feld S. 1967. Caradocian Chitinozoa from Dalarna, Sweden. Geol. Fören. Stockholm Förh., 89.

Männil R. 1971. Distribution of selected Ordovician chitinozoan assemblages and species in Northern Europe and their stratigraphical evaluation. In: Colloque ordovicien-silurien, Mem. Bureau Rech. Géol. et Min., No. 73.
Институт геологии
Академии наук Эстонской ССР
Поступнла в редакцию
14/XII 1971

R. MÄNNIL

\section{ROOTSI JA BALTIKUMI OLEMVIRU KIHTIDE KORRELATSIOON KITINOSOADE ALUSEL}

Tuginedes kitinosoade juhtvormide levikule Fjäcka, Kandava-25 ja Värska profiilis, eristatakse ülemviru kihtide uuritud lōigus viis kitinosoade biostratigraafilist ühikut (joon., I-V), käsitletakse nende karakteristikat ning vastavust lademetele, arvestades stratigraafiliselt oluliste graptoloidide leide. Täpsustatakse kukruse, idavere ja jōhvi lademe biostratigraafilisi piire. 
R. MÄNNIL

\section{CHITINOZOAN CORRELATION OF THE UPPER VIRUAN (MIDDLE ORDOVICIAN) ROCKS OF SWEDEN AND THE EAST BALTIC AREA}

The distribution of eight Upper Viruan chitinozoan species is demonstrated in the following sections (Fig.): (1) Fjäcka section, Dalarna (after Laufeld, 1967), (2) Kandava boring No. 25, Western Latvia, and (3) Värska boring, South-eastern Estonia. Most of the mentioned species seem to represent good index fossils and their vertical ranges may be considered as zones (e. g., zone of Conochitina tigrina, zone of Eremochitina dalbyensis); in other cases distinct repetitive zones here tentatively referred to as zonules, may be useful in correlations (e. g. zonule A of Desmochitina sp. n.). In the Upper Viruan sequence studied five chitinizoan zonation units are distinguished (Fig., I-V), unit I corresponding to the uppermost beds of the Kukruse Stage $\left(\mathrm{C}_{\mathrm{II}}\right)$, II - to the type section part of the Idavere Stage $\left(\mathrm{C}_{I I I}\right)$, III and IV - to the Jōhvi Stage $\left(D_{I}\right)$, and V - to the Keila Stage $\left(D_{I I}\right)$. The upper part of the unit V of the Kandava-25 and Värska core sections, characterized by the presence of Fungochitina fungiformis and Desmochitina sp. n. (zonule B) seems to correspond to the Saue Beds ( $D_{I I} S$ ) of the North Estonian sequence. According to the correlation of the conodont zonation of the Fjäcka section with the graptolite zones (Bergström, 1971a, b), the upper boundary of the Nemagraptus gracilis zone must be situated within the limits of ithe upper half of the chitinozoan unit I (=Conochitina tigrina zone). This seems to be in a good accordance with the finds of characteristic graptoloid species in the units I (Nemagraptus sp., Amplexograptus bekkeri, Orthograptus uplandicus), II (Pseudoclimacograptus scharenbergi f. typica) and III-V (Amplexograptus cf. fallax) in the East Baltic sections. 